\title{
Empirical assessment of allozyme and RAPD variation in Pinus sylvestris (L.) using haploid tissue analysis
}

\author{
ALFRED E. SZMIDT*, XIAO-RU WANG \& MENG-ZHU LU \\ Department of Forest Genetics and Plant Physiology, Swedish University of Agricultural Sciences, S-901 83, Umeå, \\ Sweden
}

\begin{abstract}
We analysed 20 allozyme and 22 putative random amplified polymorphic DNA (RAPD) loci in two populations of Pinus sylvestris (L.) from northern Sweden. Genotypes for individual allozyme and RAPD loci were inferred from segregation patterns in haploid macrogametophytes. Therefore, it was possible to distinguish between homo- and heterozygotes carrying a RAPD fragment and to estimate directly the frequencies of RAPD fragments. The percentage of polymorphic loci and the expected and observed heterozygosity were lower for allozymes than for RAPDs. Average fixation indices for both types of markers were negative indicating a heterozygote excess over panmictic expectations. The apportionment of genetic variation within and among the investigated populations was similar for allozymes and RAPDs and showed that most of the variation resided within populations. RAPD genotypes inferred from haploid material were subsequently converted to diploid phenotypes and used to estimate indirectly the frequencies of RAPD fragments. Gene diversity measurements derived from indirectly estimated RAPD frequencies were distinctly lower than those based on directly estimated RAPD frequencies. This result was caused by the absence of the null homozygote at many loci which appeared as monomorphic in the diploid data set. Population differentiation coefficients based on the indirectly estimated RAPD frequencies were not concordant with those based on directly estimated RAPD frequencies. Our present results indicate that when complete genotype information can be obtained, RAPD analysis provides genetic information similar to that revealed by analysis of allozyme variation. On the other hand, our results are concordant with theoretical results suggesting that analysis of RAPD variation in diploid material can produce unreliable estimates of population-genetic parameters.
\end{abstract}

Keywords: allozymes, gene diversity, Pinus sylvestris, population differentiation, RAPDs.

\section{Introduction}

The random amplified polymorphic DNA (RAPD) technique (Williams et al., 1990; Welsh \& McClelland, 1990) is an increasingly popular tool in genetic studies. Unfortunately, population analysis with RAPD data is hampered by the generally dominant character of RAPD variation which precludes zygosity inference and direct estimation of allele frequencies. As noted by Lynch \& Milligan (1994), this enhances the sampling variance associated with individual loci as well as inducing bias in estimation of population-genetic parameters.

When only diploid material is available for analy-

* Correspondence. sis, frequencies of RAPD fragments are estimated by indirect methods employing the observed frequency of individuals lacking the fragment, i.e. the frequency of null homozygotes (Clark \& Lanigan, 1993; Liu \& Furnier, 1993; Lynch \& Milligan, 1994). In this approach it is assumed that the population under study is in a Hardy-Weinberg equilibrium (HWE). When data for codominant markers are available, the estimated RAPD allele frequency can be corrected for potential deviations from HWE (Chong et al., 1994). Studies employing allozymes suggest that wind-pollinated conifers, including Pinus sylvestris (L.), generally show only modest departures from HWE for this type of marker (Szmidt \& Muona, 1985; Plessas \& Strauss, 1986). This suggests that the same may be true for 
RAPD markers (Wu et al., 1995). To our knowledge, this suggestion has never been tested empirically. Likewise, there have been no attempts to estimate population-genetic parameters using RAPD frequencies derived from complete genotype information. Conifers are particularly well suited to this purpose, because such information can be obtained by the analysis of segregation of RAPD fragments in haploid macrogametophytes.

Another issue addressed in several recent studies on RAPD variation is the relative merit of RAPD data as compared to other types of genetic markers such as allozymes and RFLPs (Liu \& Furnier, 1993; Chong et al., 1994; Thormann et al., 1994; Wu et al., 1995). For instance, it has been suggested that RAPDs may be more useful for detecting population differentiation than allozymes (Wu et al., 1995). Without complete genotype information, it is difficult to evaluate these merits properly.

In the present study, we analysed allozyme and RAPD variation in haploid macrogametophytes for the same set of individuals from two populations of $P$. sylvestris. Our objective was to determine the relative merits of RAPD markers for population-genetic studies. In particular, we were interested in the following questions: (i) is the HWE assumption appropriate for RAPD markers; (ii) are the population-genetic parameters based on RAPD frequencies inferred from haploid and diploid material concordant; and (iii) do RAPDs provide reliable indices of population differentiation?

\section{Materials and methods}

\section{Plant material}

Half-sib seed samples were collected in northern Sweden from two populations of $P$. sylvestris, in Svartberget and Korpilombolo. Twenty trees were sampled from each population. To determine the genotype of individual trees, allozyme and RAPD segregation patterns were analysed in eight single macrogametophytes for each of the 40 trees. Assuming a Mendelian 1:1 segregation, such a sample size is sufficient for the detection of heterozygotes with 99.2 per cent probability (Morris \& Spieth, 1978).

\section{Allozyme and DNA analysis}

Nine enzyme systems encoded by 20 loci were analysed. Isoenzyme extraction, separation and staining procedures were as described previously (Szmidt, 1984 and references therein). Total DNA from individual macrogametophytes was extracted as described by Doyle \& Doyle (1990) and suspended in TE buffer (10 mm Tris- $\mathrm{HCl}, 0.1 \mathrm{~mm}$ EDTA, pH 7.5). The PCR reaction and amplification conditions were as described previously (Lu et al., 1995). Amplification was carried out using a programmable thermocycler (PTC100; MJ Research Inc.). Two random primers (OPA9 and OPA10) were screened in each of the 40 half-sib samples. The primers were purchased from Operon Technologies (Alameda, CA, USA). The amplification products were separated in 1.4 per cent agarose gel in $0.5 \times$ TBE buffer (0.045 м Tris-borate, 0.001 м EDTA, pH 8.0). The banding patterns were visualized under UV light and photographed using a Polaroid camera. The DNA standard was a $1 \mathrm{~kb}$ ladder (BRL). Sizes of the amplified fragments were estimated using the algorithm developed by Schaffer \& Sederoff (1981). The reproducibility of the amplification products was tested twice for each sample and primer.

\section{Data scoring and analysis}

Amplified fragments, named by the primer used and the molecular weight in base pairs (bp), were scored as presence $(A)$ or absence $(a)$ of a fragment as described by $\mathrm{Lu}$ et al. (1995). In haploid macrogametophytes of $P$. sylvestris most RAPD fragments segregate in proportions expected for a dominant Mendelian trait and can be regarded as separate gene loci (Lu et al., 1995). The allozyme and RAPD genotypes inferred from haploid macrogametophytes were used for direct estimation of corresponding allele frequencies (hereafter referred to as direct frequencies).

Our previous study has demonstrated that genotypes for individual RAPD loci inferred from haploid macrogametophytes are generally concordant with the corresponding diploid phenotypes expected for a dominant marker (Lu et al., 1995). Therefore, to calculate RAPD frequencies for diploid material, genotypes inferred from haploid macrogametophytes were converted to diploid phenotypes assuming dominance. Thus all $A A$ homozygotes and $A a$ heterozygotes were scored as individuals with a fragment whereas the $a a$ homozygotes were scored as individuals without a fragment. This set of diploid data was then used to estimate RAPD frequencies indirectly (hereafter referred to as indirect frequencies), as described by Lynch \& Milligan (1994).

\section{Statistical methods}

The observed allozyme and RAPD frequencies, as 
well as indirect RAPD frequencies, were used for estimation of the following gene diversity parameters: percentage of polymorphic loci $(P)$, unbiased expected heterozygosity $\left(H_{\mathrm{E}}\right)$, observed heterozygosity $\left(H_{\mathrm{O}}\right)$ and unbiased genetic distance (D) (Nei, 1987). Observed heterozygosities were corrected for macrogametophyte sampling (Morris $\&$ Spieth, 1978). Fixation indices $(F)$ were computed as described by Curie-Cohen (1982). $\chi^{2}$-tests were used to examine conformance of $F$ estimates to Hardy-Weinberg expectations. $H_{\mathrm{O}}$ and $F$ could be calculated only for allozymes and the direct RAPDs. Calculations were made using release 1.7 of the Blosys-1 program (Swofford \& Selander, 1981). Coefficients of gene differentiation $\left(G_{\mathrm{ST}}\right)(\mathrm{Nei}, 1987)$ were calculated using allozyme and putative RAPD loci that were polymorphic in at least one population. A locus was considered polymorphic when the frequency of the most common allele did not exceed 0.95. To limit the sampling bias resulting from the dominant character of RAPDs, Lynch \& Milligan (1994) have recommended the restriction of RAPD analyses to loci for which the null homozygote frequency is more than $3 / N$, where $N$ is the number of individuals sampled in a population. With the sample size of 20 used in the present study this restriction applied to null homozygotes whose incidence was above 0.15 . Therefore, genetic parameters based on indirect and direct RAPDs were also calculated for only those loci that satisfied this restriction.

\section{Results}

\section{Allozymes vs. direct RAPDs}

The two primers used in the present study revealed 22 reproducible RAPD loci. The size of fragments amplified by these primers ranged from $0.23-1.4 \mathrm{~kb}$. An example of the RAPD profiles generated by the primers used in this study is presented in Fig. 1. Of the 20 allozyme and 22 putative RAPD loci examined, 16 and 21 loci, respectively, were polymorphic in at least one population. Fourteen allozyme loci were polymorphic in each of the two analysed populations. Twenty putative RAPD loci were polymorphic in the Svartberget population and 19 loci were polymorphic in the Korpilombolo population (Table 1). The mean variability measures $\left(P, H_{\mathrm{E}}\right.$ and $\left.H_{\mathrm{O}}\right)$ for allozymes were lower than similar measures for RAPDs (Table 2).

Average fixation indices for allozyme and RAPD markers were negative indicating heterozygote excess over panmictic expectations (Table 3). This excess was more pronounced for RAPDs than for allozymes. Three RAPD loci (OPA9-340, OPA9-400 and OPA10-1300) showed a statistically significant $(P<0.05)$ excess of heterozygotes in the Svartberget population. In the Korpilombolo population, this excess was significant at two loci (OPA9-450 and OPA10-1250). There was much variation among allozyme loci with respect to the $F$ estimates. On the other hand, $F$ estimates for RAPDs were more uniform among loci (Table 3).

The genetic distance separating the Svartberget and Korpilombolo populations was low for allo-

(a)

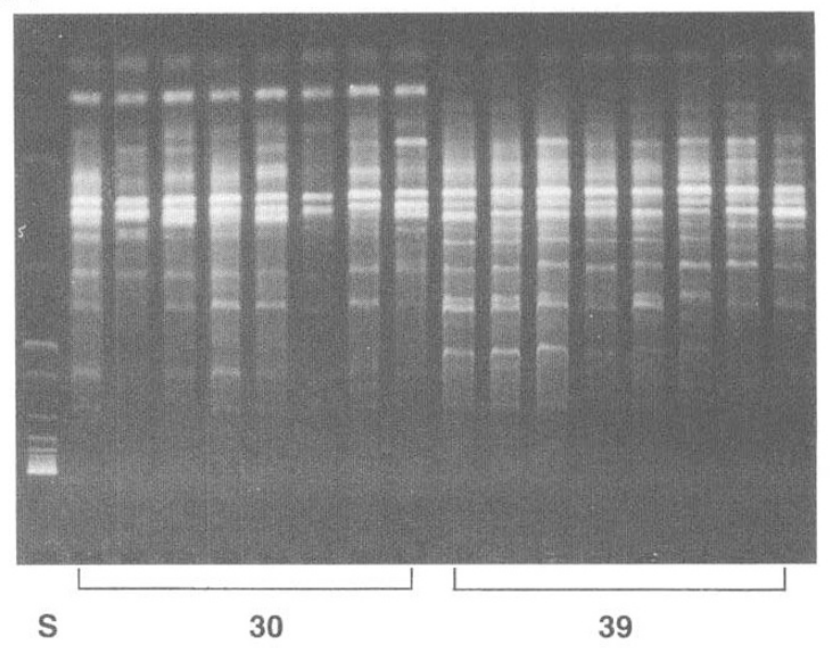

(b)

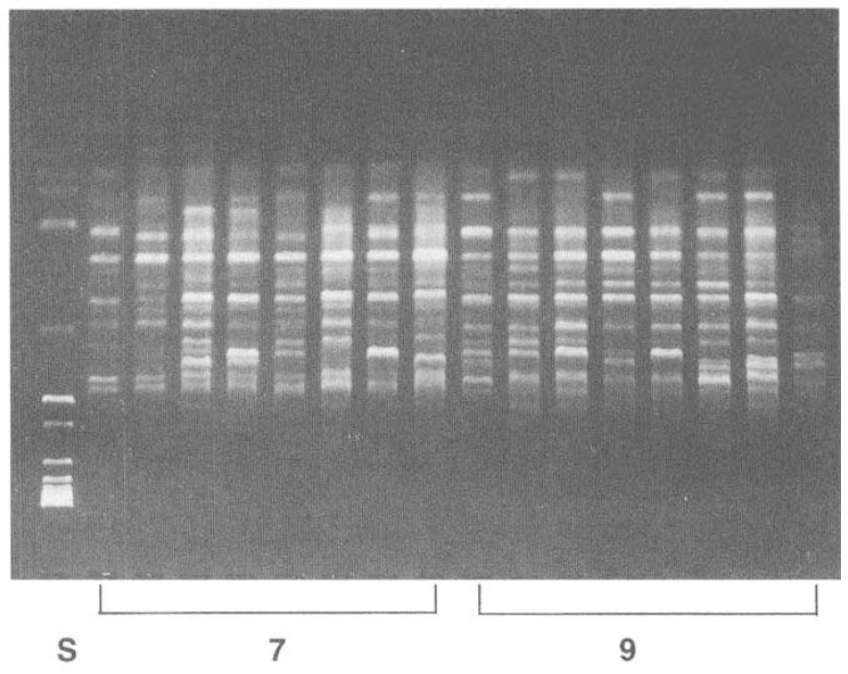

Fig. 1 RAPD profiles in haploid macrogametophytes from individual trees of Pinus sylvestris generated by (a) the OPA9 and (b) OPA10 primers. The leftmost lane contains a $1 \mathrm{~kb}$ DNA ladder. Trees are indicated by accession numbers. 
Table 1 Frequencies of RAPD fragments in Pinus sylvestris estimated from haploid macrogametophytes $(\mathrm{H})$ and diploid profiles (D)

\begin{tabular}{|c|c|c|c|c|c|c|c|}
\hline \multirow{2}{*}{$\begin{array}{l}\text { Population } \\
\text { locus }\end{array}$} & & \multicolumn{3}{|c|}{ Svartberget } & \multicolumn{3}{|c|}{ Korpilombolo } \\
\hline & & $n$ & $\mathrm{H}$ & $\mathrm{D}$ & $n$ & $\mathrm{H}$ & $\mathrm{D}$ \\
\hline \multirow[t]{2}{*}{ OPA9-230 } & $A$ & 20 & 0.975 & 1.000 & 18 & 1.000 & 1.000 \\
\hline & $a$ & & 0.025 & 0.000 & & 0.000 & 0.000 \\
\hline \multirow[t]{2}{*}{ OPA9-320 } & $A$ & 20 & 0.375 & 0.401 & 18 & 0.194 & 0.215 \\
\hline & $a$ & & 0.625 & 0.599 & & 0.806 & 0.785 \\
\hline \multirow[t]{2}{*}{ OPA9-340 } & $A$ & 20 & 0.325 & 0.401 & 18 & 0.389 & 0.463 \\
\hline & $a$ & & 0.675 & 0.599 & & 0.611 & 0.537 \\
\hline \multirow[t]{2}{*}{ OPA9-400 } & $A$ & 20 & 0.575 & 0.746 & 18 & 0.694 & 0.647 \\
\hline & $a$ & & 0.425 & 0.254 & & 0.306 & 0.353 \\
\hline \multirow{2}{*}{ OPA9-450 } & $A$ & 20 & 0.750 & 1.000 & 20 & 0.675 & 1.000 \\
\hline & $a$ & & 0.250 & 0.000 & & 0.325 & 0.000 \\
\hline \multirow[t]{2}{*}{ OPA9-650 } & $A$ & 20 & 0.825 & 1.000 & 20 & 0.950 & 1.000 \\
\hline & $a$ & & 0.175 & 0.000 & & 0.050 & 0.000 \\
\hline \multirow[t]{2}{*}{ OPA9-700 } & $A$ & 20 & 0.650 & 0.665 & 20 & 0.700 & 1.000 \\
\hline & $a$ & & 0.350 & 0.335 & & 0.300 & 0.000 \\
\hline \multirow[t]{2}{*}{ OPA9-750 } & $A$ & 20 & 0.900 & 1.000 & 20 & 0.925 & 1.000 \\
\hline & $a$ & & 0.100 & 0.000 & & 0.075 & 0.000 \\
\hline \multirow[t]{2}{*}{ OPA9-800 } & $A$ & 20 & 0.725 & 0.746 & 20 & 0.925 & 1.000 \\
\hline & $a$ & & 0.275 & 0.254 & & 0.075 & 0.000 \\
\hline \multirow[t]{2}{*}{ OPA9-1300 } & $A$ & 20 & 0.800 & 1.000 & 20 & 0.900 & 1.000 \\
\hline & $a$ & & 0.200 & 0.000 & & 0.100 & 0.000 \\
\hline \multirow[t]{2}{*}{ OPA9-1380 } & $A$ & 20 & 0.525 & 0.598 & 20 & 0.525 & 0.490 \\
\hline & $a$ & & 0.475 & 0.402 & & 0.475 & 0.510 \\
\hline \multirow[t]{2}{*}{ OPA10-410 } & $A$ & 18 & 0.611 & 0.733 & 19 & 0.553 & 0.656 \\
\hline & $a$ & & 0.389 & 0.267 & & 0.447 & 0.344 \\
\hline \multirow[t]{2}{*}{ OPA10-480 } & $A$ & 18 & 0.306 & 0.370 & 19 & 0.500 & 0.430 \\
\hline & $a$ & & 0.694 & 0.630 & & 0.500 & 0.570 \\
\hline \multirow[t]{2}{*}{ OPA10-520 } & $A$ & 20 & 0.800 & 1.000 & 19 & 0.816 & 1.000 \\
\hline & $a$ & & 0.200 & 0.000 & & 0.184 & 0.000 \\
\hline \multirow[t]{2}{*}{ OPA10-600 } & $A$ & 20 & 0.925 & 1.000 & 19 & 0.895 & 1.000 \\
\hline & $a$ & & 0.075 & 0.000 & & 0.105 & 0.000 \\
\hline \multirow[t]{2}{*}{ OPA10-750 } & $A$ & 20 & 0.825 & 1.000 & 20 & 0.875 & 1.000 \\
\hline & $a$ & & 0.175 & 0.000 & & 0.125 & 0.000 \\
\hline \multirow[t]{2}{*}{ OPA10-800 } & $A$ & 20 & 0.850 & 1.000 & 20 & 0.974 & 1.000 \\
\hline & $a$ & & 0.150 & 0.000 & & 0.026 & 0.000 \\
\hline \multirow[t]{2}{*}{ OPA10-850 } & $A$ & 20 & 0.600 & 0.665 & 20 & 0.575 & 0.598 \\
\hline & $a$ & & 0.400 & 0.335 & & 0.425 & 0.402 \\
\hline \multirow[t]{2}{*}{ OPA10-1200 } & $A$ & 20 & 0.775 & 0.746 & 19 & 0.974 & 1.000 \\
\hline & $a$ & & 0.225 & 0.254 & & 0.026 & 0.000 \\
\hline OPA10-1250 & $A$ & 20 & 0.350 & 0.401 & 20 & 0.425 & 0.541 \\
\hline & $a$ & & 0.650 & 0.599 & & 0.575 & 0.459 \\
\hline OPA10-1300 & $A$ & 20 & 0.675 & 1.000 & 19 & 0.737 & 0.740 \\
\hline & $a$ & & 0.325 & 0.000 & & 0.263 & 0.260 \\
\hline OPA10-1400 & $A$ & 20 & 0.975 & 1.000 & 20 & 0.950 & 1.000 \\
\hline & $a$ & & 0.025 & 0.000 & & 0.050 & 0.000 \\
\hline
\end{tabular}

$n$, plant sample size for each locus; $A$, fragment present; $a$, fragment absent.

zymes and RAPDs $(D=0.006$ and 0.003 , respectively). The $G_{\mathrm{ST}}$ coefficients for allozyme and RAPD markers were similar and showed that most of the variation resided within populations (Table 4).

\section{Direct RAPDs vs, indirect RAPDs}

The null homozygote was absent at 10 RAPD loci identified in this study (data not shown). Consequently, only 12 of the 22 putative RAPD loci 
Table 2 Mean measures of genetic diversity at 16 allozyme and 22 putative RAPD loci for the investigated populations of Pinus sylvestris

\begin{tabular}{lcccc}
\hline $\begin{array}{c}\text { Population } \\
\text { marker }\end{array}$ & $n \pm \mathrm{SE}$ & $P$ & $H_{\mathrm{O} \pm \mathrm{SE}}$ & $H_{\mathrm{E} \pm \mathrm{SE}}$ \\
\hline $\begin{array}{c}\text { Svartberget } \\
\text { Allozymes }\end{array}$ & $19.8 \pm 0.2$ & 70.0 & $0.269 \pm 0.054$ & $0.262 \pm 0.054$ \\
RAPD* & $19.8 \pm 0.1$ & 90.9 & $0.444 \pm 0.043$ & $0.356 \pm 0.030$ \\
RAPD & $19.8 \pm 0.1$ & 50.0 & $-\S$ & $0.223 \pm 0.049$ \\
RAPD & $19.7 \pm 0.3$ & 100.0 & - & $0.482 \pm 0.007$ \\
Korpilombolo & & & & \\
Allozymes & $19.7 \pm 0.2$ & 70.0 & $0.296 \pm 0.058$ & $0.276 \pm 0.053$ \\
RAPD* & $19.3 \pm 0.2$ & 86.4 & $0.343 \pm 0.050$ & $0.298 \pm 0.039$ \\
RAPD $\dagger$ & $19.3 \pm 0.2$ & 40.9 & - & $0.192 \pm 0.051$ \\
RAPD $\ddagger$ & $19.2 \pm 0.4$ & 100.0 & - & $0.480 \pm 0.025$ \\
\hline
\end{tabular}

$n$, mean sample size per locus; $P$, percentage of polymorphic loci; $H_{\mathrm{O}}$, observed heterozygosity; $H_{\mathrm{E}}$, unbiased expected heterozygosity.

${ }^{*}$ Based on direct RAPD frequencies, 0.95 criterion.

$\uparrow$ Based on indirect RAPD frequencies, 0.95 criterion.

$\$$ Based on indirect RAPD frequencies, for loci that satisfied the 0.15 restriction.

$\S$ Cannot be calculated from frequency data alone.

Table 3 Fixation indices for allozyme and putative RAPD loci in the investigated populations of Pinus sylvestris

\begin{tabular}{|c|c|c|c|c|c|}
\hline \multirow[b]{2}{*}{ Locus } & \multicolumn{2}{|c|}{ Population } & \multirow[b]{2}{*}{ Locus } & \multicolumn{2}{|c|}{ Population } \\
\hline & Svartberget & Korpilombolo & & Svartberget & Korpilombolo \\
\hline Lap-1 & $-\dagger$ & - & OPA9-230 & 一 & - \\
\hline Lap-2 & - & -0.053 & OPA9-320 & -0.173 & -0.241 \\
\hline Got-1 & - & - & OPA9-340 & $-0.481^{*}$ & -0.403 \\
\hline Got-2 & -0.414 & -0.303 & OPA9-400 & $-0.535^{*}$ & 0.084 \\
\hline$G D h$ & 0.026 & 0.200 & OPA9-450 & -0.333 & $-0.481^{*}$ \\
\hline FEst & -0.129 & -0.042 & OPA9-650 & -0.212 & -0.053 \\
\hline$A c o$ & -0.053 & - & OPA9-700 & -0.099 & -0.429 \\
\hline Pgm-1 & -0.081 & -0.081 & OPA9-750 & -0.111 & -0.081 \\
\hline Pgm-2 & - & - & OPA9-800 & -0.129 & -0.081 \\
\hline Pgi-1 & - & - & OPA9-1300 & -0.250 & -0.111 \\
\hline Pgi-2 & 0.134 & -0.053 & OPA9-1380 & -0.303 & 0.098 \\
\hline Pgd-1 & 0.134 & -0.103 & OPA10-410 & -0.403 & -0.384 \\
\hline Pgd-2 & -0.212 & -0.190 & OPA $10-480$ & -0.440 & 0.263 \\
\hline$A P h$ & -0.176 & -0.290 & OPA10-520 & -0.250 & -0.226 \\
\hline$S D h-1$ & -0.187 & -0.178 & OPA $10-600$ & -0.081 & -0.118 \\
\hline$S D h-2$ & -0.081 & - & OPA $10-750$ & -0.212 & -0.143 \\
\hline$M D h-1$ & - & -0.053 & OPA10-800 & -0.176 & - \\
\hline$M D h-2$ & -0.330 & $-0.538^{*}$ & OPA10-850 & -0.250 & -0.125 \\
\hline$A D h-1$ & -0.173 & -0.099 & OPA10-1200 & -0.004 & - \\
\hline$M n r$ & $0.626^{*}$ & 0.000 & OPA10-1250 & -0.319 & $-0.535^{*}$ \\
\hline & & & OPA10-1300 & $-0.481^{*}$ & -0.086 \\
\hline & & & OPA10-1400 & - & -0.053 \\
\hline Mean: & -0.065 & -0.127 & Mean: & -0.262 & -0.163 \\
\hline
\end{tabular}

$\uparrow$ Not computed when the frequency of the most common homozygote exceeds 0.98 .

${ }^{*} \chi^{2}$-test, $P<0.05$. 
Table 4 Comparison of $G_{\mathrm{ST}}$ coefficients for Pinus sylvestris based on allozymes, direct and indirect frequencies of RAPD fragments

\begin{tabular}{lllcc}
\hline $\begin{array}{l}\text { Allozyme } \\
\text { locus }\end{array}$ & & $\begin{array}{l}\text { RAPD } \\
\text { locus }\end{array}$ & Direct & Indirect \\
\hline Lap-2 & 0.004 & OPA9-230 & 0.013 & $\mathbf{-}^{*}$ \\
GDh & 0.005 & OPA9-320 & 0.040 & 0.041 \\
FEst & 0.011 & OPA9-340 & 0.004 & 0.004 \\
Aco & 0.026 & OPA9-400 & 0.015 & 0.012 \\
Pgi-2 & 0.024 & OPA9-450 & 0.007 & - \\
Pgd-1 & 0.135 & OPA9-650 & 0.039 & - \\
$P g d-2$ & 0.020 & OPA9-700 & 0.003 & 0.201 \\
APh & 0.009 & OPA9-750 & 0.002 & - \\
SDh-1 & 0.025 & OPA9-800 & 0.069 & 0.145 \\
$S D h-2$ & 0.013 & OPA9-1300 & 0.020 & - \\
$M D h-1$ & 0.004 & OPA9-1380 & 0.000 & 0.012 \\
$M D h-2$ & 0.006 & OPA10-410 & 0.003 & 0.007 \\
$A D h-1$ & 0.001 & OPA10-480 & 0.039 & 0.004 \\
$M n r$ & 0.019 & OPA10-520 & 0.000 & - \\
& & OPA10-600 & 0.003 & - \\
& & OPA10-750 & 0.005 & - \\
& & OPA10-800 & 0.048 & - \\
& & OPA10-850 & 0.001 & 0.005 \\
& & OPA10-1200 & 0.090 & 0.145 \\
& & OPA10-1250 & 0.006 & 0.020 \\
Mean & 0.022 & OPA10-1300 & 0.005 & 0.149 \\
Mean $\dagger$ & - & OPA10-1400 & 0.004 & - \\
\hline
\end{tabular}

${ }^{*}$ Locus monomorphic.

$†$ Based on 12 polymorphic loci for both direct and indirect RAPDs.

remained polymorphic (0.95 criterion) following conversion of the RAPD genotypes inferred from haploid macrogametophytes to diploid phenotypes (Table 1). The $P$ and $H_{\mathrm{E}}$ estimates derived from indirect RAPD frequencies at these loci were lower than those based on the direct RAPDs (Table 2). In the diploid data set, the frequency of null homozygotes was above 0.15 for only six loci (data not shown). The measures of intrapopulation diversity based on the indirect RAPD frequencies for these six loci were much higher than similar measures based on the direct RAPD frequencies (Table 2).

The estimates of population differentiation based on the indirect frequencies for polymorphic RAPD loci were different from those based on the direct RAPD frequencies. The genetic distance between the Svartberget and Korpilombolo populations $(D=0.019)$ was several times greater than distance coefficients based on the direct RAPD frequencies. The average $G_{\mathrm{ST}}$ for indirect RAPD frequencies was much higher than the average $G_{\mathrm{ST}}$ for the direct RAPD frequencies and allozymes (Table 4). The high $D$ and $G_{\mathrm{ST}}$ obtained for the indirect RAPD frequencies were mainly caused by four loci: OPA9-700, OPA9-800, OPA10-1200 and OPA10-1300. Two of these loci (OPA9-800 and OPA10-1200) showed true differences between the Svartberget and Korpilombolo populations (Table 4). However, the other two loci had a much lower $G_{\mathrm{ST}}$ for the direct than for the indirect RAPDs (Table 4). This discrepancy was caused by the absence of the null homozygote at the OPA10-1300 locus in the Svartberget population, and at the OPA9-700, OPA9-800 and OPA10-1200 loci in the Korpilombolo population (data not shown). Consequently, in the diploid data set the Svartberget population becomes fixed for the presence of the OPA10-1300 fragment and the Korpilombolo population becomes fixed for the presence of the fragments at OPA9-700, OPA9-800 and OPA10-1200 
loci. When analysis of population differentiation was based on six loci that satisfied the 0.15 restriction, the $D$ and $G_{\mathrm{ST}}$ coefficients were low (0.001 and 0.013 , respectively).

Based on the multilocus allozyme genotypes it was possible to discriminate between all individuals from the Svartberget and Korpilombolo populations. The same was true for the RAPD multilocus genotypes inferred from analysis of macrogametophytes. Based on the diploid RAPD phenotypes it was still possible to discriminate between 95 per cent of the investigated individuals (data not shown).

\section{Discussion}

\section{Allozymes vs. direct RAPDs}

Earlier studies have suggested that RAPD analysis usually reveals a high number of polymorphic loci (Carlson et al., 1991; Bucci \& Menozzi, 1993; Nelson et al., 1994; Lu et al., 1995). Our present results are concordant with these suggestions. Although only two primers were employed in the present analysis, as many as 22 putative RAPD loci could be identified.

The present analysis of RAPD variation in haploid macrogametophytes provides the first direct estimates of population-genetic parameters based on this new type of marker. In plants, RAPDs generally show similar or higher levels of polymorphism than other types of markers (Liu \& Furnier, 1993; Chong et al., 1994; Wu et al., 1995). Our present measurements of genetic variability based on the direct RAPD frequencies are concordant with these results. All but one putative RAPD loci identified in the present study were polymorphic ( 0.95 criterion) and produced higher measures of gene diversity than allozymes. This result can be explained by more random and efficient genome sampling by RAPDs than by allozymes which are restricted to genes coding for proteins. The RAPD distance and $G_{\mathrm{ST}}$ coefficients for the investigated populations were low and comparable to similar measures for $P$. sylvestris populations from Scandinavia based on allozymes (Szmidt \& Muona, 1985; Szmidt \& Wang, 1993; this study). Low levels of population differentiation for both types of markers found in this study can be explained by unrestricted gene flow among populations and the relatively recent history of $P$. sylvestris in Scandinavia.

It has been suggested that because of the generally neutral character of allozyme and RAPD markers potential deviations from HWE should affect both types of markers in a similar way (Chong et al., 1994). Results of the present study provide the first empirical evidence for this suggestion. Fixation indices for both allozyme and RAPD loci were negative, indicating an excess of heterozygotes over panmictic expectations. In conifers, inbred individuals commonly express inbreeding depression and are removed from a population during the early stages of life (Eriksson et al., 1973). The material analysed in this study came from two mature stands of $P$. sylvestris. Selection against the more homozygous, relatively inbred individuals was the likely cause of the negative fixation indices observed in this and other studies (e.g Szmidt \& Muona, 1985; Plessas \& Strauss, 1986; Kärkkäinen \& Savolainen, 1993). It thus appears that when complete genotype information is available, analysis of RAPD variation yields population genetic parameters that are comparable to those based on allozymes. Nearly all individuals analysed in this study could be distinguished by RAPD profiles generated with only two primers. This confirms the usefulness of RAPD markers for fingerprinting purposes suggested in many previous studies (e.g. Koller et al., 1993; Keil \& Griffin, 1994).

\section{Direct vs. indirect RAPDs}

Theoretical studies suggest that the usefulness of RAPDs is limited when only diploid material is available (Clark \& Lanigan, 1993; Lynch \& Milligan, 1994). Our present results provide the first empirical information on this subject. Dominance is widely observed for RAPD fragments in $P$. sylvestris and other forest conifers (Carlson et al., 1991; Bucci \& Menozzi, 1993; Lu et al., 1995). Because of this property of RAPDs, gene frequency estimates for such loci derived from diploid material are less accurate than those obtained with codominant markers. When only diploid material is available and the null homozygote is not detected, a locus is scored as fixed for the fragment presence. As demonstrated by Lynch \& Milligan (1994) the bias in the estimation of the null-allele frequency because of small sample size can be substantial when the null homozygote is rare. Our results revealed that in the diploid data set, 10 of the 21 polymorphic RAPD loci appeared as fixed for the fragment presence because of the absence of null homozygotes. Consequently, intrapopulational diversity parameters derived from the indirect RAPD frequency were much lower than similar parameters derived from complete genotype information. Statistical methods to analyse population differentiation using RAPD data include the assumption that the genotype frequencies are in 
HWE (Lynch \& Milligan, 1994). Under this assumption, 2 to 10 times more individuals should be sampled per RAPD locus than per codominant allozyme locus to reduce the fraction of loci that will yield biased parameter estimates in diploid material (Lynch \& Milligan, 1994). Most of the putative RAPD loci identified in the present study had negative $F$-values indicating that the frequency of homozygotes was substantially lower than expected under HWE. This result implies that RAPD analysis in diploid material would probably require a much larger sample size than that suggested by Lynch \& Milligan (1994). Recently, Chong et al. (1994) have proposed a new method for the estimation of nullallele frequencies for putative RAPD loci corrected for deviations from HWE. In this method, frequencies of null-alleles are estimated using the $F_{\text {IS }}$ value (Wright, 1965) previously estimated with codominant markers, e.g. allozymes for the same population. The generally higher deviations from HWE for the RAPD loci than for allozyme loci found in our study indicate that such correction may be insufficient. The necessity of carrying out additional analyses employing codominant markers further limits the feasibility of this approach.

Lynch \& Milligan (1994) have suggested that in diploid material unbiased estimates of populationgenetic parameters can be achieved with RAPDs provided the analysis is restricted to markers that are not too common. In our diploid data set, this restriction was satisfied for only a few highly polymorphic loci and caused substantial overestimates of gene diversity measures. Moreover, the loci that are rejected may differ from population to population (Lynch \& Milligan, 1994). In the present study, such differences were observed for several RAPD loci and produced biased estimates of population differentiation.

It has been suggested that RAPDs may be particularly useful in genetic conservation programmes, where they could allow distinct gene pools to be recognized from small population samples (Wu et al., 1995). Results of the present study clearly warn against such application of RAPD markers when only diploid material is available for analysis. Both earlier theoretical and the present empirical results demonstrate that RAPD analysis can produce seriously biased estimates of genetic parameters when only diploid material is available for analysis and the sample size is small. In conifers, this bias can be compounded by deviations from HWE, especially those involving heterozygote excess.

\section{Acknowledgements}

We thank Ingabritt Carlsson and Roger Granbom for technical assistance. This study was sponsored with grants from the Swedish Council for Forestry and Agricultural Research (SJFR), the National Research Council (NFR) and the Kempe Foundation.

\section{References}

BUCCI, G. AND MENOZZI, P. 1993. Segregation analysis of random amplified polymorphic DNA (RAPD) markers in Picea abies Karst. Mol. Ecol., 2, 227-232.

CARLSON, J. E., TUlSIERAM, L. K., GLAUBITZ, J. C., LUK, V. W. K., KAUfFELDT, C. AND RUTLEDGE, R. 1991. Segregation of random amplified DNA markers in $F_{1}$ progeny of conifers. Theor. Appl. Genet., 83, 194-200.

CHONG, D. K. X., YANG, R.-C. AND YEH, F. C. 1994. Nucleotide divergence between populations of trembling aspen (Populus tremuloides) estimated with RAPDs. Curr. Genet., 26, 374-376.

Clark, A. G. AND LANigAN, C. M. s. 1993. Prospects for estimating nucleotide divergence with RAPDs. Mol. Biol. Evol., 10, 1096-1111.

CURIE-COHEN, M. 1982. Estimates of inbreeding in a natural population: a comparison of sampling properties. Genetics, 100, 339-358.

DOYLE, J. J. AND DOYLE, J. L. 1990. Isolation of plant DNA from fresh tissue. Focus, 12, 13-15.

ERIKSSON, G., SCHELANDER, B. AND ÅKEBRAND, v. 1973. Inbreeding depression in an old experimental plantation of Picea abies. Hereditas, 73, 185-194.

KÄRKKÄINEN, K. AND SAVOLAINEN, O. 1993. The degree of early inbreeding depression determines the selfing rate at the seed stage: model and results from Pinus sylvestris (Scots pine). Heredity, 71, 160-166.

KEIL, M. AND GRIFFIN, A. R. 1994. Use of random amplified polymorphic DNA (RAPD) markers in the discrimination and verification of genotypes in Eucalyptus. Theor. Appl. Genet., 89, 442-450.

KOLLER, B., LEHMANN, A., McDERMOTT, J. M. AND GESSLER, C. 1993. Identification of apple cultivars using RAPD markers. Theor. Appl. Genet., 85, 901-904.

LIU, z. AND FURNIER, G. R. 1993. Comparison of allozyme, RFLP, and RAPD markers for revealing genetic variation within and between trembling aspen and bigtooth aspen. Theor. Appl. Genet., 87, 97-105.

LU, M.-Z., SZMIDT, A. E. AND WANG, X.-R. 1995. Inheritance of RAPD fragments in haploid and diploid tissues of Pinus sylvestris (L.). Heredity, 74, 582-589.

LYNCH, M. AND MILligAN, B. 1994. Analysis of population genetic structure with RAPD markers. Mol. Ecol., 3, 91-99.

MORRIS, R. W. AND SPIETH, P. T. 1978. Sampling strategies for using female gametophytes to estimate heterozygosities in conifers. Theor. Appl. Genet., 51, 217-222. 
NEI, M. 1987. Molecular Evolutionary Genetics. Columbia University Press, New York.

NELSON, C. D., KUBISIAK, T. L., STINE, M. AND NANCE, W. L. 1994. A genetic linkage map of longleaf pine (Pinus palustris Mill) based on random amplified polymorphic DNAs. J. Hered., 85, 433--439.

PLESSAS, M. E. AND STRAuSs, s. H. 1986. Allozyme differentiation among populations, stands, and cohorts in Monterey pine. Can. J. Forest Res., 16, 1155-1164.

SCHAFFER, H. E. AND SEDEROFF, R. 1981. Improved estimation of DNA fragment lengths from agarose gels. Analyt. Biochem., 115, 113-122.

SWOFFORD, D. L. AND SELANDER, R. B. 1981. BIOSYS-1: a FORTRAN program for the comprehensive analysis of electrophoretic data in population genetics and systematics. J. Hered., 72, 281-283.

SzmidT, A. E. 1984. Genetic Studies of Scots Pine (Pinus Sylvestris L.) Domestication by Means of Isozyme Analysis. $\mathrm{PhD}$ thesis, Faculty of Forestry, Swedish University of Agricultural Sciences, Umeå.

SZMIDT, A. E. AND MUONA, O. 1985. Genetic effects of Scots pine (Pinus sylvestris L.) domestication. Lect. Notes in Biomath., 60, 241-252.
SZMIDT, A. E. AND WANG, X.-R. 1993. Molecular systematics and genetic differentiation of Pinus sylvestris (L.) and $P$. densiflora (Sieb. et Zucc.). Theor. Appl. Genet., 86, 159-165.

Thormann, C. E., ferreira, M. E., CAMARgo, L. E. A., TIVANG, J. G. AND OSBORN, T. C. 1994. Comparison of RFLP and RAPD markers to estimating genetic relationships within and among cruciferous species. Theor. Appl. Genet., 88, 973-980.

WELSH, J. AND MCCLELlAND, M. 1990. Fingerprinting genomes using PCR with arbitrary primers. Nucl. Acids Res., 18, 7213-7218.

WILLIAMS, J. G. K., KUBELIK, A. R., LIVAK, K. J., RAFALSKI, J. A. AND TINGEY, s. v. 1990. DNA polymorphisms amplified by arbitrary primers are useful as genetic markers. Nucl. Acids Res., 18, 6531-6535.

WRIGHT, s. 1965 . The interpretation of population structure by F-statistics with special regard to systems of mating. Evolution, 19, 395-420.

WU, J., WAGNER, S., KRUTOVSKII, K. AND STRAUSS, S. H. 1995. Strong differentiation of RAPD markers among populations of knobcone pine (Pinus attenuata). Forest Genet. (in press). 